\title{
Estudo dos percursos de exploração de um material multimidiático para leitura de um poema com realidade aumentada por alunos o Ensino Fundamental II
}

\author{
Study of exploration paths of a multimedia material \\ designed for reading a poem with augmented reality by \\ Middle School students
}

\author{
Rita de Fátima Rodrigues Guimarães \\ Universidade Estadual de Campinas, Campinas, São Paulo, Brasil
}

\begin{abstract}
Resumo: O desenvolvimento das tecnologias digitais promove mudanças nas práticas sociais contemporâneas. Sendo assim, outras reflexões são necessárias para melhor compreender mudanças nas formas de agir, interagir e construir sentidos com textos agregados a suportes eletrônico-digitais. Este artigo apresenta os percursos de exploração, por alunos do Ensino Fundamental II, de um material multimidiático para leitura de um poema com Realidade Aumentada. Os objetivos deste trabalho são: descrever os modos pelos quais os alunos manuseiam, interagem e reagem aos recursos da tecnologia existentes no material e de que forma esses modos podem impactar construções de sentidos. Ademais, apresenta uma comparação do percurso desse material com percursos de navegação de outras escritas hipermidiáticas, como os hipertextos. Para isso, os principais aparatos teóricos considerados são: mídias imersivas (cf. AZUMA, 1997, 2017; LIU et al., 2017); escritas hipermidiáticas (cf. LEMKE, 2010; SIGNORINI, 2013); os novos letramentos (LANKSHEAR e KNOBEL, 2011); e a metodologia de pesquisa qualitativa (YIN, 2009). Os resultados apontam para o uso das interações típicas da RA pelos participantes, o aumento da motivação e a ampliação das construções de sentidos pela nova forma de interação disponibilizada pela RA.
\end{abstract}

Palavras-chave: Leitura; Percursos; Novos Letramentos; Poemas; Realidade Aumentada

\begin{abstract}
The development of digital technologies promotes changes in contemporary social practices. Thus, other reflections are necessary to better understand changes in the ways of acting, interacting and constructing meanings with texts added to electronic-digital supports. This paper presents the paths of exploration, by Middle School students, of a multimedia material for reading a poem with Augmented Reality. The objectives of this paper are: describing the ways in which students handle, interact, and react to the technological resources in the material, as well as how these ways can impact
\end{abstract}

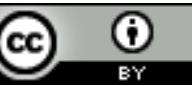


on the construction of meaning. Moreover, it presents a comparison of the path of this material with navigation paths from other hypermedia writings, such as hypertexts. To this end, the main theoretical apparatuses considered are immersive media (cf. AZUMA, 1997, 2016; LIU et al., 2017); hypermedia writings (cf. LEMKE, 2010; SIGNORINI, 2013); new literacies (LANKSHEAR and KNOBEL, 2011); and qualitative research methodology (YIN, 2009). The results point to the use of typical AR interactions by the participants, to increased motivation, and to constructions of meaning that are amplified by the new form of interaction made available by AR.

Keywords: Reading; Paths; New Literacies; Poems; Augmented Reality

\section{Introdução}

O desenvolvimento das tecnologias digitais impacta consideravelmente as práticas sociais contemporâneas, principalmente a partir da década de 90, quando a Internet e os dispositivos eletrônicos móveis iniciaram seu processo de popularização. Esse impacto envolve as maneiras rotineiras pelas quais as pessoas agem, manuseiam objetos, concebem tarefas, compreendem o mundo. Assim, as mudanças tecnológicas afetam o modo pelo qual as pessoas constroem sentidos e a maneira como produzem, distribuem, trocam e recebem textos por meios eletrônicos, ampliando novas reflexões no campo dos novos letramentos (cf. LANKSHEAR, KNOBEL, 2011).

A partir desse contexto, este artigo apresenta um estudo, que faz parte de uma pesquisa qualitativa ${ }^{1}$, dos percursos de exploração de alunos no $7^{\circ}$ ano do Ensino Fundamental II durante o uso de um material multimidiático, envolvendo a leitura de um poema e a tecnologia de Realidade Aumentada (RA). Os objetivos deste trabalho são: descrever os modos pelos quais os alunos manuseiam, interagem e reagem aos recursos da tecnologia existentes no material e de que forma esses modos impactam as construções de sentidos; apresentar uma comparação do percurso desse material com percursos de navegação de outras escritas hipermidiáticas, como os hipertextos.

Assim, esse artigo concentra-se no aspecto denominado pelos novos letramentos de modo ontológico e, mais especificamente, ao que é designado por technical stuffs, ou seja, maneiras de interagir, na recepção ou na produção, com recursos providos pela

\footnotetext{
${ }^{1}$ Este estudo é parte da pesquisa descrita em Guimarães (2019).
} 
tecnologia e relacionados aos textos pós-tipográficos (cf. LANKSHEAR e KNOBEL, 2011).

Quanto ao interesse pelo uso e estudo de mídias imersivas ${ }^{2}$, pesquisas apontam para a importância do crescimento de investigações na área de educação, envolvendo, principalmente, o Ensino Fundamental e Médio (cf. LIU et al., 2017), e para poucos trabalhos envolvendo o campo de estudos da linguagem (cf. SIRAKAYA e ALSANCAK SIRAKAYA, 2018). Com relação às pesquisas na educação com RA, trabalhos, como o de Bower et al. (2014), mostram o aumento da motivação dos alunos e melhoria na aquisição de conhecimentos, quando expostos a materiais e conteúdos incorporados com essa mídia. Ademais, há indicações de que a RA pode se alinhar à tendência cada vez mais crescente de acesso à informação e à Internet por meio de dispositivos móveis, permitindo a interação do usuário com o virtual de forma mais próxima do que seria o modo de interação com objetos no mundo real (cf. NMC/CoSN Horizon Report, 2017).

Segundo Azuma (1997, 2017), a RA é uma variação da Realidade Virtual (RV). Enquanto a RV permite uma completa imersão do usuário em um ambiente computacionalmente sintetizado, de modo que ele não veja o mundo real ao seu entorno, a RA permite ao usuário ver o mundo real com objetos virtuais sobrepostos, constituindo a cena real. Sistemas de RA possibilitam a interação em tempo real com os objetos virtuais; a busca pelo alinhamento perfeito entre as imagens $3 \mathrm{D}$ reais e virtuais, de forma que o usuário tenha a ilusão de que os objetos virtuais existem no ambiente real. Assim, a RA complementa a realidade ao invés de substituí-la completamente, como na RV. Um exemplo do emprego dessa tecnologia foi, na área de entretenimento, o jogo Pokémon Go em RA, muito comentado no ano de 2016 e ilustrado pela figura 1.

\footnotetext{
${ }^{2}$ Mídias imersivas são aquelas que permitem graus de imersão aos usuários com o virtual. Por exemplo: Realidade Virtual (RV); Realidade Aumentada (RA) e Ambientes Virtuais Multiusuários. (cf. DEDE; JACOBSON; RICHARDS, 2017, p. 4)
} 
Figura 1 - Cena do jogo Pokémon Go com RA

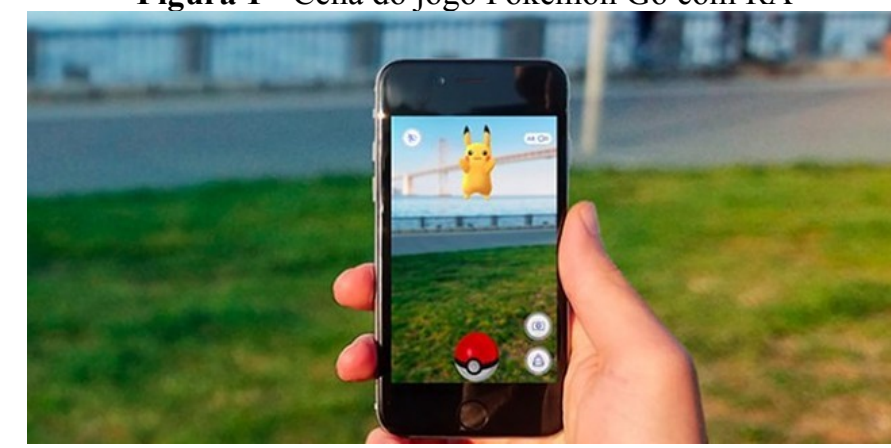

Fonte: https://www.flickr.com/photos/iphonedigital/28286906571

Para a realização da pesquisa que originou este trabalho foi elaborado um material multimidiático, pois não foi encontrado um material envolvendo a leitura de um poema e a RA. Além disso, trabalhos como de Gebara (2002) e Sorrenti (2013), e dados empíricos sobre a leitura de poemas - de outra etapa da investigação que originou esse trabalho mostraram uma menor familiaridade dos estudantes com textos de poemas quando comparados aos textos em prosa. Ademais, a RA se mostrava alinhada aos textos poéticos pelo seu caráter enigmático.

Portanto, dessa pesquisa, descrita em Guimarães (2019), surgiu a possibilidade de descrever como seriam também os percursos de exploração do material constituído de um texto tipográfico do poema e outros conteúdos pós-tipográficos.

Assim, organizamos a apresentação deste artigo nas seguintes seções: O Material Multimidiático, seção na qual descrevo os objetos virtuais de RA (e mídias utilizadas) e os principais recursos disponíveis pela tecnologia de RA para que o aluno possa acessálos e navegar por seus conteúdos informacionais. Na seção Novos Letramentos faço uma breve descrição do conceito de modo ontológico descrito por Lankshear e Knobel (2011). Em seguida, apresento a seção de Metodologia, na qual descrevo a abordagem metodológica, métodos, a identificação do local, dos participantes e a descrição da etapa da pesquisa. Em Análise dos dados e resultados, apresento detalhes da análise e dos principais resultados. Por fim, nas Considerações finais, concluo com reflexões finais deste estudo. 


\section{0 material multimidiático}

O design do material multimidiático envolveu a escrita em variadas linguagens e mídias ${ }^{3}$ realizada por múltiplos autores, compondo uma equipe multidisciplinar ${ }^{4}$ (cf. GUIMARÃES, 2019).

Esse material, assim como algumas aplicações de RA, utiliza uma imagem na cena real para a projeção dos objetos virtuais sobrepostos ao ambiente. Dessa forma, o material multimidiático da pesquisa que originou este trabalho é constituído de um marcador - um papel impresso com o poema "A Bailarina", de Iêda Dias (1993), o qual será a imagem utilizada pela RA para projeção dos objetos virtuais, que são: a Bailarina Azul; A Pequena Bailarina de Quatorze Anos; o vídeo sobre a Origem do Balé; e o vídeo sobre o artista Edgar Degas.

$\mathrm{Na}$ figura 2, a imagem de um dos tablets utilizado pelos alunos com o papel impresso do poema na mesa, e a Bailarina Azul, a qual é um dos conteúdos informacionais e objeto virtual 3D animado, pertencente ao espaço entre a tela e o papel, permitindo a ideia de imersão do objeto à cena pelo leitor. $\mathrm{O}$ contorno em vermelho mostra os ícones - na tela do tablet - para acesso aos conteúdos informacionais em RA.

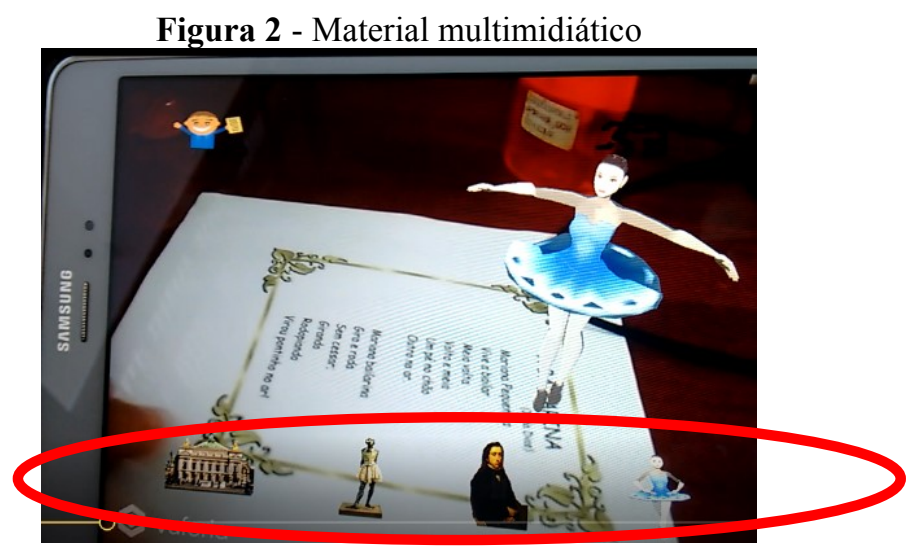

Nota: A demonstração dos possíveis percursos de exploração dos alunos com material multimidiático pode ser vista em: https://tinyurl.com/226f233w

Fonte: Guimarães (2019)

\footnotetext{
${ }^{3} \mathrm{O}$ design do material multimidiático envolveu: a modelagem de objetos 3D com animação; a edição de vídeos com Windows Movie Maker; a integração de todas as mídias (vídeos e objetos 3D) por meio do Unit3D.

${ }^{4}$ Profissional de Letras e profissionais da área de Computação.
} 
Os objetos virtuais que surgem sobrepostos à cena real, como mencionamos, são dois objetos virtuais 3D (a Bailarina Azul - objeto com animação - e a escultura d'A Pequena Bailarina de Quatorze Anos) e dois vídeos (a história do balé clássico e a história de Edgar Degas).

A incorporação da RA e o design dos objetos virtuais são formas de ampliação, "formas aumentadas" de proporcionar novas leituras em múltiplos modos e mídias. Quando do design do material foram considerados: (i) dados empíricos de uma aula de leitura e interpretação de poemas ${ }^{5}$ dos alunos em outra fase da pesquisa; (ii) pressupostos teóricos de leitura literária (cf. LANGLADE, 2013) pelos quais o texto literário pode somente existir quando efetivamente "produzido" pelo leitor - a ideia da obra literária passar existir quando o leitor lhe confere sua leitura particular; (iii) o entendimento do poema como "molde" para várias imitações ou representações das ações humanas em diferentes espaços e tempos, ou seja, o conceito de mimèsis da Poética de Aristóteles; (iv) a temática do balé clássico como uma das possíveis temáticas para o poema; (v) por fim, o caráter lúdico na leitura de poemas para crianças, justamente pela aspecto mais enigmático da linguagem poética.

Assim, os vídeos foram pensados como ampliadores da possível temática do poema: o balé clássico. As narrativas foram construídas para aproximar os alunos de situações reais distantes e próximas do espaço e do tempo deles. O texto do poema surge como um "gatilho" para todas essas representações - dos vídeos e dos modelos 3D. E $A$ Pequena Bailarina de Quatorze Anos permite a ampliação da visualização da obra do artista Degas em formato 3D. Já a Bailarina Azul foi criada a partir da interpretação de um grupo de alunos sobre o poema e seu último verso "Virou pontinho no ar!"”, pois se tratava do movimento de rodopio da bailarina. Foi o objeto virtual que surgiu da produção do próprio leitor (cf. LANGLADE, 2013) e que pode ser soprado por ele, permitindo que a Bailarina Azul se afaste de sua "plateia" até poder ser comparada a um pontinho no ar.

Os recursos de interação explorados neste artigo são: a movimentação do marcador, em especial de rotação, quando da visualização de objetos virtuais 3D; e a movimentação do tablet, em especial de aproximação, afastamento quando da visualização dos vídeos, e a movimentação ao entorno dos objetos virtuais quando em

\footnotetext{
${ }^{5}$ Detalhamentos sobre a criação do material multimidiático, e a leitura do poema antes e após o uso da RA podem ser encontrados em Guimarães, 2019.

${ }_{6}^{6}$ Poema pode ser encontrado em Sorrenti (2013, p. 97).
} 
3D. Além dessa interatividade, típica de aplicações de RA, foi criado no design do material o recurso de soprar a Bailarina Azul, associado ao lado lúdico e enigmático próprios textos poéticos.

$\mathrm{Na}$ sequência, são apresentados alguns conceitos dos novos letramentos que justificam a inclusão de estudos como este, ou seja, de percursos de exploração do material multimidiático.

\section{Novos letramentos}

O crescimento e a popularidade de uma perspectiva sociocultural nos estudos da linguagem e das ciências sociais, nas décadas de 80 e 90, impactaram fortemente o entendimento conceitual e teórico de práticas envolvendo textos (cf. LANKSHEAR, KNOBEL, 2011). Com isso, estudiosos e pesquisadores dos letramentos passam a compreendê-los como fenômeno social e, mais especificamente, descritos por Lankshear e Knobel (2011) como “formas socialmente reconhecidas pelas quais as pessoas geram, comunicam e negociam sentidos, como membros de Discursos, através de textos codificados e disponibilizados por uma mídia" (p. 33).

Assim, a adição do termo "novos" ao se referir a letramentos pode ser compreendida de uma maneira paradigmática, ou seja, o termo "novo" está associado à forma de passar a investigar e pensar os letramentos como fenômeno social. Ou pode ser compreendido de um segundo modo, o ontológico, dividido em duas partes. A primeira diz respeito ao aumento das tecnologias digitais (technical stuffs) e à emergência de formas textuais e de produção de textos pós-tipográficos, os quais são diferentes dos letramentos impressos "convencionais" e, portanto, envolvem novas práticas sociais que mudam a forma de produzir, distribuir, trocar e receber textos por meios eletrônicos.

Estão incluídos nas novas produções, os textos multimodais que chegam por código digital e incluem som, texto, imagem, vídeo, animação ou combinação desses modos. Dessa forma, a maneira ontológica de compreender os novos letramentos diz respeito às práticas mediadas por textos em formatos pós-tipográficos, por exemplo: o uso de hyperlinks para acesso a textos que podem ser multimodais, o uso de emoticons em um chat on-line; a manipulação de um mouse para mover-se pelo texto; ou ainda a 
navegação por mundos tridimensionais ou on-line ${ }^{7}$ (p. 28-29). Outro aspecto ontológico para compreender os novos letramentos está associado a uma segunda questão: a do novo ethos, o qual, de modo simplificado, está relacionado às novas formas pelas quais as pessoas ganham e compartilham conhecimento, criam espaços de afinidades, atitudes mais colaborativas, mais compartilhadas, por exemplo, em oposição a formas mais individualizadas, centradas no autor, estáveis e lineares (cf. GEE, 2004).

Postos esses conceitos, passamos à descrição da metodologia e dos percursos de exploração dos alunos participantes deste estudo, considerando o modo ontológico relacionado a technical stuffs, no caso, a RA.

\section{Metodologia}

O percurso de exploração do material multimidiático faz parte de uma pesquisa qualitativa de estudo de caso $^{8}$, na qual identificamos um fenômeno pouco investigado, com caráter particular e contemporâneo (cf. YIN, 2009), o qual deveria ser descrito e explorado, ou seja: a leitura de um poema com a incorporação de RA.

Ademais, a investigação que originou este estudo foi realizada em contexto real de uso do material, mas em condições de algum controle porque havia a indicação do uso da aplicação de RA em um contexto determinado e delimitado, como: o tempo máximo de exploração do material pelo aluno ${ }^{9}$ e do uso do sopro como uma interação possível com o objeto virtual Bailarina Azul.

Participaram dessa pesquisa 32 alunos - as duas salas de $7^{\circ}$ ano de uma escola privada da cidade de Jundiaí, estado de São Paulo, dedicada ao Ensino Infantil e ao Fundamental.

Este artigo descreve a pesquisa depois da criação do material multimidiático e no momento de exploração do material pelos alunos.

A coleta de registros foi realizada no período das aulas de Língua Portuguesa dos estudantes. Foram disponibilizados tablets com a aplicação de RA e o marcador para

\footnotetext{
${ }^{7}$ Novos letramentos existem também sem uso das tecnologias digitais.

${ }^{8}$ Aprovado pelo Comitê de Ética em Pesquisas (CAAE: 75993317.9.0000.5404).

${ }^{9} \mathrm{O}$ tempo máximo para o uso do material era de 10 minutos.
} 
utilização autônoma dos alunos (sem interferência da pesquisadora, dos professores ou dos colegas). Depois do uso do material, os alunos foram entrevistados.

Os métodos para coleta dos registros deste estudo foram: as videogravações para captura do cenário de uso e das interações dos alunos com o material; os $\log s$ - registros gerados automaticamente pela própria aplicação de RA - contendo as interações com os ícones da aplicação e as entrevistas semiestruturadas.

A formação do corpus de análise foi realizada com auxílio do software de análise qualitativa Atlas.ti, e os dados deste artigo advém de um processo de categorizações estabelecidas nas videogravações, $\log s$ e entrevistas. Por meio dessas categorizações (por códigos do Atlas.ti), foi possível identificar como ocorreu o percurso de exploração do material quanto: aos tipos de interações utilizadas e as mais utilizadas; ao número de acessos aos objetos virtuais pelos toques nos ícones (e sequência desses toques), comparando acessos a vídeos e acessos aos objetos 3D; e, por fim, ao tempo de permanência no uso dos objetos virtuais, comparando tempos entre os vídeos e os objetos $3 \mathrm{D}$.

\section{Análise dos dados e resultados}

O corpus de análise apresenta as seguintes interações dos alunos por meio das videogravações: (i) movimento ou giro do marcador; (ii) movimentação do tablet; (iii) interação com objeto virtual por meio do sopro; (iv) tentativa de pegar o objeto virtual como se ele fosse real; (v) interações praticadas quando em sistemas multimídias tradicionais, como tentar movimentar os objetos pelo toque na tela.

A análise dos dados encaminha para o predomínio das interações próprias de aplicações de $\mathrm{RA}^{10}$, ou seja, uso de interações que se assemelham às interações em situações reais (rotações de objetos, sopro, movimentações do tablet como se fosse uma lupa). Portanto, os alunos, ao navegarem pelo material, vivenciaram interfaces diferentes das tradicionais, como o uso do mouse, ícone de zoom, toque na tela para arrastar o virtual.

Em relação às novas interfaces, o número de interações com a Bailarina Azul, por meio do sopro, sobressaiu às outras interações. Por meio das entrevistas, verificamos o interesse por esse recurso lúdico e o aumento de motivação para pensar no sentido da

1030 de 32 participantes utilizaram as interações típicas da RA. 
animação e compará-la com a temática do balé clássico, com o poema ou mesmo com o último verso: "Virou pontinho no ar". Ressaltamos que sem a interação de soprar a bailarina, pelo aluno, não é inicializada a animação desse objeto, o qual foi construído para simular uma interpretação de um grupo de alunos (o movimento de rodopiar da bailarina). Portanto, existindo a animação há a ampliação das interpretações da polissemia própria animação e das interpretações construídas pelos leitores. Com isso, constatamos a importância da interação nas variações de construções de sentidos que ocorrem tanto no processo de inicialização da animação quanto pela polissemia da imagem e do movimento.

Quantos às interações ${ }^{11}$ de rotação do marcador, de tentativa de pegar os objetos virtuais ou de movimentação do tablet, elas ocorreram, predominantemente, com os objetos virtuais 3D (Bailarina Azul e A Pequena Bailarina de Quatorze Anos), o que faz mais sentido porque para os vídeos os movimentos de afastar e aproximar, como uma lupa, são mais naturais. Além disso, percebemos que os alunos compreenderam a coexistência dos objetos virtuais à cena real que é o local de leitura do poema.

A boa adaptação às novas interfaces, por meio das interações analisadas, é um resultado importante porque quase $60 \%$ dos participantes declararam não conhecer a RA, nem à RV. Ademais, $88 \%$ dos participantes reconhecem no material a sensação de imersão dos objetos virtuais no seu espaço real e os manipularam com naturalidade (cf. GUIMARÃES, 2019, p. 102).

Quanto aos acessos aos ícones ${ }^{12}$ da aplicação, os alunos se dividiram quanto às sequências das apresentações, no entanto, a maior parte deles acessou a todos os conteúdos disponibilizados. Os objetos 3D, pelo aspecto lúdico e polissêmico, foram revisitados mais vezes que os vídeos, pois como os alunos relataram nas entrevistas: as linguagens presentes nos vídeos eram mais fáceis para compreensão e, fora do ambiente escolar, os vídeos eram muito acessados, depois dos games; os vídeos proporcionaram ganhos de conhecimento e ampliaram as discussões, como sobre o próprio poema. No quadro 1, trechos das entrevistas com os participantes.

\footnotetext{
${ }^{11}$ Interações como de toque na tela para manipular os objetos virtuais foram raras.

12 Imagens dos ícones não continham legendas.
} 
Quadro 1 - Trechos de algumas transcrições das entrevistas com os alunos.

Andy: Eu não sabia que o balé era algo muito antigo, e das mulheres quando elas não eram valorizadas realmente. A valorização da mulher, que o pintor fez, na época, foi bem inovadora, como disse. Mary: Eu aprendi sobre a história, fiquei muito impressionada e a escultura...

Fred: eu aprendi do pintor é... porque fica mais fácil de entender com as imagens.(do vídeo)

Lara: ...vi também a história do balé, como surgiu, dos artistas ...Você vê que quando sabe a história daquilo, eu acho que você vai ter interesse por aquilo e vai quere saber mais.

Entrevistador: Você aprendeu alguma coisa de novo?

Jiren: Ah. aprendi a história... a história e que poema é legal.

E: Ah! Então deixou o poema legal?

Jiren: Pela primeira vez!

Fonte: Guimarães $(2019$, p. 138, 139)

Quanto ao tempo de permanência dos alunos em cada objeto virtual, destacamos a dispersão dos alunos em cada tipo de mídia. Alguns se concentraram mais nos vídeos, outros, nos objetos $3 \mathrm{D}$, o que demostrou um potencial do material para diferentes perfis de alunos. Além do mais, de modo geral, entendemos pelas entrevistas que os vídeos foram importantes para revelar conhecimento sobre as histórias - do balé e de Degas, ampliando o repertório dos alunos sobre a temática. Já os objetos 3D prenderam a atenção dos alunos pelos efeitos da tecnologia de poder observar e manipular esses objetos sobre o papel, e pelo aspecto enigmático da sua "leitura", caso da Bailarina Azul, a qual também relacionaram com o poema ou com os conteúdos informacionais (cf. GUIMARÃES, 2019, p. 137).

Quanto aos tempos de permanência nos dois vídeos, foram praticamente iguais. Já nos objetos 3D, houve maior tempo destinado à Bailarina Azul em comparação com a escultura de Degas, provavelmente pela informação enciclopédica dessa última, relacionada ao vídeo sobre Degas. Assim, observamos a importância da interação com esse objeto para detalhamento da informação recebida pelo vídeo e complementar a ele. No quadro 2, a fala da aluna sobre d'A Pequena Bailarina de Quatorze Anos.

Quadro 2: Transcrições das entrevistas.

Alícia: A estátua me chamou a atenção...

Alicia: Porque mostrava os detalhes que nem eu vi do pintor que foi ele que fez. eu cliquei pra ver ... Eu vi tinha todos os detalhes que eu tinha escutado, os efeitos do tecido, eu gostei bastante.

Fonte: Guimarães (2019, p. 134)

Com relação à Bailarina Azul, ela exigiu mais tempo para sua interpretação e possíveis relações com os conteúdos apresentados. 
$\mathrm{E}$, por fim, quanto à leitura do poema, apenas $13 \%$ dos participantes não se lembravam do texto. Metade da turma declarou ter lido o poema, e $46 \%$ se lembravam dele da aula anterior à criação do material.

Assim, estabelecidos os percursos de exploração dos alunos, traçamos algumas comparações, como o hipertexto e a hipermídia. (cf. GUIMARÃES, 2019, p. 92-94)

Durante o momento de uso do material, os alunos ficaram restritos à lógica programada pela aplicação de RA, e não há o que Lemke (2002) define para o hipertexto como transversals, ou seja, as múltiplas possibilidades de trajetórias na rede do hipertexto (LEMKE, 2001, p.300). Além disso, como define Signorini (2013):

[...] a principal característica do hipertexto e da hipermídia de modo geral é o fato de serem constituídos pelo verbal escrito, dentre outras linguagens, e põe estruturas de navegação que só se realizam, ou se concretizam, na seleção na ciclagem de links do leitor internauta. (p. 200)

Assim, a semelhança do material multimidiático com o hipertexto ocorre pela presença de links nos ícones da aplicação, acessados pelo toque do aluno, para concretizar a visualização dos objetos virtuais. Entretanto, a programação desse material não permite $^{13}$ o encadeamento de links como nos websites, por exemplo.

Portanto, o material é um modelo mais restrito de percurso de exploração quanto ao número de nós e encadeamento de links, mas são percursos ilimitados dentro do circuito apresentado na figura 3 , e não são determinadas as sequências realizadas entre os nós. O leitor/usuário é livre para escolher os caminhos dentro do circuito no qual os nós periféricos representam os objetos virtuais e o nó central, o marcador com o poema.

Figura 3: Modelo de possíveis percursos do material multimidiático.

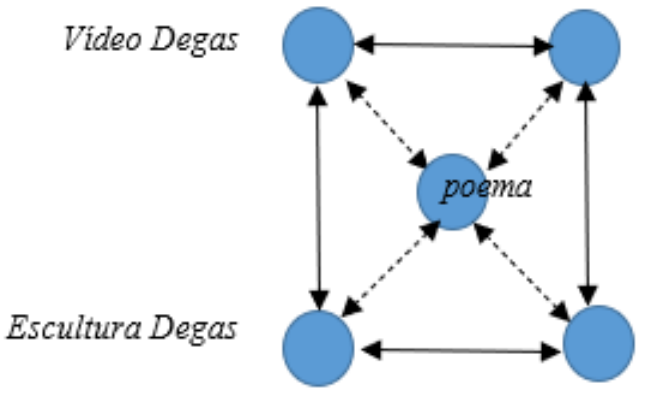

Bailarina Azul

Video Origem

Fonte: Guimarães (2019, p. 93)

${ }^{13}$ Não é uma restrição da RA, mas do design do material. 
Outra característica peculiar do percurso de exploração do material é que o virtual não está restrito à tela do dispositivo móvel ou do computador, como os hipertextos ou a hipermídia. Os percursos de exploração e visualização dos conteúdos informacionais atingem o espaço entre a página impressa e a tela. Os percursos de exploração passam pela tela e se deve considerar a continuidade desse percurso na interação com os objetos virtuais (rotação do marcador ou movimentação do tablet) no espaço entre papel e tela. É nesse percurso de exploração que há infinitas e não determinadas formas de recepção das informações pelo leitor/usuário. Por fim, apesar de não detectável nas videogravações, o percurso se estende à leitura do poema no marcador.

Destacamos, por fim, uma nova forma de leitura diante do texto com suporte eletrônico-digital, na qual o leitor volta a ter uma relação mais corporal no processo de leitura, como pelo sopro, na figura 4 ou da movimentação do tablet na figura 5 .

Figura 4 - Leitor/usuário sopra a Bailarina Azul que rodopia e se afasta dele.

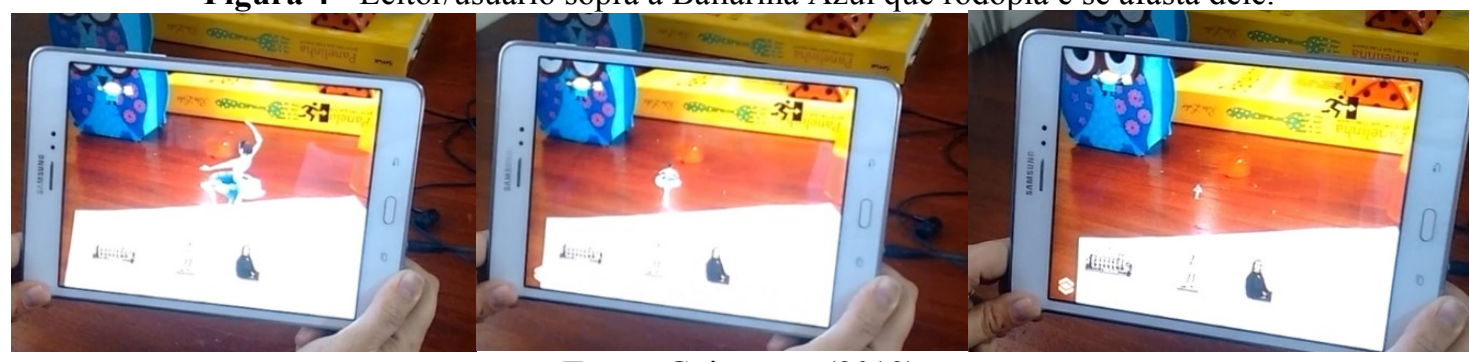

Fonte: Guimarães (2019)

Figura 5 -Leitor/usuário afasta-se do objeto virtual ou aproxima-se dele.

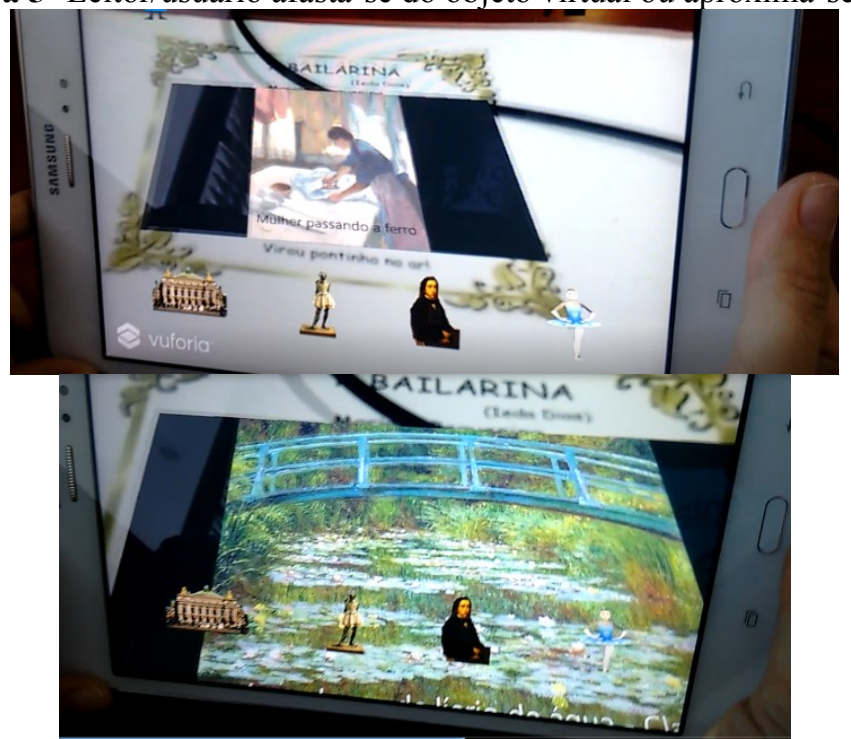

Fonte: Guimarães (2019) 


\section{Considerações finais}

O estudo dos percursos de exploração do material multimidiático - entendido como uma construção pós-tipográfica - permitiu identificar como os alunos participantes da pesquisa se apropriaram de uma nova forma de manusear e interagir com o virtual, mesmo sem contatos prévios com a RA. Os desdobramentos dessa interatividade, acesso ou tempo de permanência com o virtual revelaram diversos aspectos sobre o uso da RA com a leitura do poema. Primeiramente, a identificação da motivação dos alunos frente ao conteúdo apresentado, como demonstrado por outras pesquisas em educação em outros contextos disciplinares. Depois, o reconhecimento dos efeitos da tecnologia, de pertencimento do virtual à cena real, ampliando a leitura das imagens, reforçando o aspecto motivacional e expandindo as construções de sentidos sobre o que era apresentado, exemplificados na fala de Alícia. A escultura de Degas ou mesmo os quadros do artista, nos vídeos, permitiram observações sobre obras de artes que poderiam ser apreciadas, de maneira semelhante, somente quando em uma visitação real a um museu. Ou seja, a simulação de espaços e tempos para o leitor/usuário oferece vivências com a arte (literatura, pintura, música e outras) dentro do ambiente escolar.

Além das potencializações das informações pelo tipo de interação e de permanência no imagético, as falas das narrativas, pelas histórias, ampliaram o repertório dos alunos, constituindo ganhos de conhecimento sobre a temática escolhida do poema. A música da Bailarina Azul e a interação pelo sopro mostraram não somente a potencialidade dessa tecnologia para incorporar o lúdico, muitas vezes presente nos textos poéticos, mas também amplificaram construções de sentidos sobre as possíveis interpretações da Bailarina Azul e da sua relação com as outras leituras.

Outrossim, este trabalho apresenta uma relação do leitor/usuário com o material (pós-tipográfico) mais próxima daquela estabelecida com o livro impresso, ou seja, a possibilidade de o leitor aproximar-se para ver as imagens, folhear as páginas. Assim, parece haver uma postura do leitor diferente daquela que Chartier (1999) comenta em relação aos textos pós-tipográficos: "mais distanciada, e não corporal" (p.16). Desse modo, o estudo dos percursos de exploração mostra um processo misto de leitura tradicional com suporte eletrônico, indicando possíveis ampliações das reações, atuações do leitor e suas construções de sentidos. 


\section{Agradecimentos}

Agradeço à orientação da Profa Dra Inês Signorini e ao grupo de pesquisa "Práticas de escrita e de reflexão sobre a escrita em diferentes mídias".

\section{Referências}

AZUMA, R. T. A Survey of Augmented Reality. Presence: Teleoperators and Virtual Environments, 1997. p. 355-385.

AZUMA, R. T. Making Augmented Reality a Reality. Presence, v. 25, n. 3, 2017. p. 234-238.

Chartier, R. A aventura do livro: do leitor ao navegador. São Paulo: Editora Unesp, 1999.

BOWER, M.; HOWE, C.; McCREDIE, N.; ROBISON, A. GROVER, D. Augmented Reality in education - cases places and potential. Educational Media International, $v$. 51, n. 1, 2014. p. 1-15.

DEDE, C; JACOBSON, J.; RICHARDS, J. Introduction: Virtual, Augmented, and Mixed Realities in Education. In: LIU, D.; DEDE, C.; HUANG, J.; RICHARDS, J. (orgs). Virtual, Augmented, and Mixed Realities in Education, 2017. (Smart Computing and intelligence).

GEBARA, A. E, L. A poesia na escola. São Paulo: Cortez. 2002. (Coleção aprender e ensinar com textos, v. 10).

GEE, J. P. Situated Language and Learning: A Critique of Traditional Schooling. London: Routledge, 2004.

GUIMARÃES, R. F. R. Estudo da incorporação da Realidade aumentada na leitura de poema em duas turmas no ciclo inicial do Ensino Fundamental II. $2019.161 \mathrm{f}$. Dissertação (Mestrado em Linguística Aplicada na área de Linguagem e Educação) Instituto de Estudos da Linguagem, Universidade Estadual de Campinas, Campinas.

LANGLADE, G. O sujeito leitor, autor da singularidade da obra. In: ROUXEL, A.; LANGLADE, G.; REZENDE, N. (orgs.). Leitura subjetiva e ensino de literatura. São Paulo: Alameda, 2013. p. 25-38.

LANKSHEAR, C., KNOBEL, M. New Literacies: everyday practices and social learning. McGraw-Hill Education, Open University Press, Third Edition, 2011. 
LEMKE, J. L. Letramento metamidiático: transformando significado e mídias. Tradução de Clara Dornelles. Trabalhos em Linguística Aplicada, Campinas/SP, v. 49, n. 2, p. 455-479, 2010.

LIU, D.; DEDE, C.; HUANG, J.; RICHARDS, J. Virtual, Augmented, and Mixed Realities in Education, 2017. (Smart Computing and intelligence).

The NMC/CoSN Horizon Report: 2017 K-12. Disponível em: https://files.eric.ed.gov/fulltext/ED588803.pdf. Acesso em março de 2021.

SIGNORINI, I. Bordas e Fronteiras entre escritas grafocêntricas e hipermidiáticas. In: MOITA LOPES, L. P (org). Linguística Aplicada na Modernidade Recente. São Paulo: Parábola, 2013. p. 197-209.

SIRAKAYA, M.; ALSANCAK SIRAKAYA, D. Trends in Educational Augmented Reality Studies: A Systematic Review. Malaysian Online Journal of Educational Technology, v. 6, n. 2, p. 60-74, 2018. DOI: https://doi.org/10.17220/mojet.2018.02.005

SORRENTI, N. A poesia vai à escola - Reflexões, comentários e dicas de atividades. 2. ed. São Paulo: Autêntica, 2013. (Coleção Formação Humana na Escola, 6).

YIN, Robert K. Case Study Research: design and methods. 4. ed. USA: SAGE, 2009. (Applied Social Research methods series, 5).

Recebido em: 21 de outubro de 2020 Aceito em: 15 de março de 2021 Publicado em maio de 2021 